\title{
Correction to: Biofouling in RO Desalination Membranes
}

\author{
Nawrin Anwar, Liuqing Yang, Wen Ma, Haamid Sani Usman, \\ and Md. Saifur Rahaman
}

\section{Correction to:}

Chapter 13 in: V. S. Saji et al. (eds.),

Corrosion and Fouling Control in Desalination Industry, https://doi.org/10.1007/978-3-030-34284-5_13

The original version of the book was inadvertently published without the copyright information for Fig. 13.2 in Chap. 13. The correct figure caption has been updated in the chapter as given below:

Figure 13.2 Formation of irreversible fouling on polyamide membrane. (Reproduced the inset image with permission from Dr. Florian Beyer; Copyright @ Dr. Florian Beyer) 